\title{
THE USE OF ASSISTED AUTOGENIC DRAINAGE IN CHILDREN WITH CYSTIC FIBROSIS, A PILOT RANDOMIZED CONTROLLED STUDY.
}

The final publication will be available at IOS Press

Citation: Corten, L., Morrow, B.M. (2019). The use of assisted autogenic drainage in children with cystic fibrosis, a pilot randomized controlled study. Physiotherapy Practice and Research [in press]

\section{Authors:}

Lieselotte Corten ${ }^{1,2} \&$ Brenda M Morrow ${ }^{3}$

\section{Author affiliations:}

${ }^{1}$ Department of Health and Rehabilitation Sciences (Physiotherapy), University of Cape Town, Observatory, South Africa

${ }^{2}$ School of Health Sciences (Physiotherapy), University of Brighton, Eastbourne, United Kingdom

${ }^{3}$ Department of Paediatrics and Child Health, University of Cape Town, Rondebosch, South Africa

\section{Correspondence to:}

Dr Lieselotte Corten

University of Brighton

Robert Dodd Building, room G22

49 Darley Road, Eastbourne, BN20 7UR, United Kingdom

E-mail: I.corten@brighton.ac.uk 
3

\section{ABSTRACT}

Background: Airway clearance therapy (ACT) is standard practice to promote pulmonary mucus clearance in children with cystic fibrosis (CF). However, the efficacy of assisted autogenic drainage (AAD) in children has not been studied.

Objectives: To pilot a home-based randomized controlled trial (RCT) to compare the effects of AAD to standard ACT in children with CF aged one to eight years.

Methods: Children with CF, aged one to eight years, were randomly assigned into intervention (AAD) or control (standard ACT) groups. The ACTs were taught to parents and children, to perform twice daily for a year. Primary outcome measures were number of hospitalizations, days of hospitalization, exacerbations and days of antibiotic therapy in one year. Secondary outcome measures included spirometry, and adherence assessed on every visit (through calendar and sticker system); parental proxy health related quality of life score (EQ-5D-Y), current clinical status (CF Clinical Score), weight-, height-, and BMI-for-age z-scores assessed at baseline and after one year; and preference of ACT and mortality rates were assessed at the end of the study. At the end of the study, a self-designed one on one subjective semi-structured interview with the parent(s)/caregiver(s) regarding physiotherapy management was conducted.

Results: Of 36 children screened for inclusion, 16 were enrolled. Seven were randomly allocated to the control group (median [IQR] age 5.7 [3.0-6.0] years, four male and three female), and nine to the intervention group (median [IQR] age 5.8 [5.5-6.6] years, five male and four female). There were no significant between-group differences, however number of exacerbations revealed medium (Cohen's $d=0.55$ ) effect sizes, favoring the intervention group. Although no significant improvements were 
seen within the intervention group, large effect sizes were found for the CF subjective and total

25 clinical scores; and health related quality of life (Cohen's $d=1.07, d=0.87$, and $d=0.86$ respectively).

This pilot study identified a number of concerns, mainly poor adherence to home-therapy in both

27 arms of the study, and no participant in the intervention group solely performing AAD as per pre-set methodology, limiting interpretation of results.

Conclusion: There is a need for confirmatory, adequately powered trials to evaluate safety and efficacy of AAD in children with CF. Future research needs to also consider measures to ensure better adherence to ACT. 


\section{INTRODUCTION}

Cystic fibrosis (CF), an autosomal recessive hereditary disease, affects all exocrine glands in the body, resulting in an altered airway environment leading to a vicious cycle of reduced mucociliary clearance secretion retention, airway obstruction, secondary chest infections and inflammation; and can result in irreversible lung damage (bronchiectasis) and respiratory failure [1,2]. Airway clearance therapy (ACT) has been shown to have positive effects on pulmonary mucus clearance in children with CF [3], and has been recommended by current guidelines for the management of $\mathrm{CF}[4,5]$. However, the majority of studies investigating ACT in children with CF included children older than six years of age, with very few studies including infants and young children. In children under eight years of age, assisted autogenic drainage (AAD), a modified form of autogenic drainage (AD), may be used as it can be performed passively or active assisted [6]. This technique uses breathing at three different lung volumes; applying the principle of shear forces by producing optimal airflow in the small airways to remove secretions from peripheral to central airways, thereby theoretically preventing collapse of the small airways [7]. However, as most young patients cannot independently change the lung volumes towards the desired level, the physiotherapist manually alters the levels of breathing by applying graded pressure to the chest wall [6]. No gastro-esophageal reflux or other complications have been associated with AAD [8].

As the relative utility and superiority of individual ACTs in children younger than eight years of age is unknown, development of evidence-based information is a priority for this group of children. No randomized controlled trials (RCTs) have been published on AD or AAD in children with CF [9].

Therefore, this pragmatic study aimed to pilot a home-based RCT, to compare the effects of AAD to standard ACT in children with CF aged one to eight years. 
58

\section{Study design}

A single blinded (outcome assessor and data analyst blinded to allocation), pragmatic RCT was conducted at a multidisciplinary pediatric outpatient CF clinic. Treatment consisted of a taught home-program, executed by the parents who underwent training by the clinic's physiotherapist (see Supplement 1 for training information). The study ran from 15 January 2015 until 30 September 2016.

This study aimed to enroll 30 children to be randomly assigned (1:1 ratio) to the intervention ( $n=15)$ or control ( $n=15)$ group (see Figure 1). Sample size was determined based on the estimated patient population, between one and eight years of age, attending the clinic (personal communication with CF clinic staff).

\section{Subjects}

Children diagnosed with CF, confirmed by two positive sweat tests and/or genotype analysis, between the age of one and eight years, who were followed up at the CF clinic, were considered for inclusion in the study. Exclusion criteria were: awaiting a lung transplant, severe scoliosis or kyphosis, osteoporosis, recent history (<six months) of pneumothorax or thoracic/abdominal surgery; emphysema or active sarcoidosis, premature birth ( $\leq 30$ weeks), on anti-tuberculosis treatment, untreated/uncontrolled asthma, or known to be non-compliant to physiotherapy treatment prior to recruitment.

\section{Outcome measures}

This study's primary outcome measures were number of hospitalizations, days of hospitalization, exacerbations and days of antibiotic therapy during one year. The secondary outcome measures were: spirometry and adherence, documented with a self-designed calendar and sticker system, 
which was reviewed at each follow up visit (determined at the physician's discretion, often performed quarterly); parental proxy health related quality of life score (HRQOL) by the EuroQol- five dimensions youth version (EQ-5D-Y), validated for the South African context and valid for children with CF $[10,11]$; current clinical status by the CF clinical score (CFCS), validated in a pediatric population [12]; weight-, height-, and BMI-for-age z-scores at baseline and end of study; preference of $A C T$ ( $A A D$ versus standard $A C T$ ), using an adapted version of a standardized questionnaire designed by Jarad et al. (2010) [13] at first follow up and at the end of the study; and mortality rate at the end of the study period.

\section{Interventions}

Standard treatment, consisting of manual techniques (modified postural drainage (PD), percussion and vibration) and/or positive expiratory pressure (PEP) therapy or Flutter device and/or components of the active cycle of breathing technique (ACBT), was given to children in the control group, according to age, ability and preference[14]. The intervention group received AAD, performed in an upright position, standardizing the treatment position and optimizing use of the diaphragm, improving ventilation and influencing fatigue in infants and young children $[6,15]$. The caregiver manually increased the expiratory flow velocity and prolonged expiration towards residual volume by placing the hands on the child's chest and gently following the breathing of the child while lowering thoracic expansion [6].

In this home-based study, treatments were meant to be performed twice daily. Duration of the treatments varied between five to 30 minutes, depending on the child's tolerance (parents were educated on how to identify signs of respiratory distress, hypoxemia and infection). Parents were asked to carry out the intervention every day around the same time, once in the morning and once in the afternoon or evening. 
Institutional ethical approval (HREC 648/2013) and approval from the medical superintendent at the research site was obtained. Participants were recruited during the weekly CF-clinic, over a 20 month time period. Eligibility of children was determined by screening the patients' medical files. Written informed consent was obtained from the parent(s) and assent was obtained from children older than five years of age. An overview of the study procedure can be found in Supplementary file 3. All participants went through the same procedure unless otherwise indicated in Supplementary file 3.

At the first follow up visit, approximately three months after recruitment, it became evident that compliance to a daily diary (indicating when, for how long, and which ACTs were given; and the reason(s) for terminating the intervention) was poor. Therefore, parents and patients were asked to adhere to a self-designed monthly calendar and sticker system. For each completed treatment, the child placed a sticker on the calendar. At each CF-clinic visit (quarterly for most participants), parents were asked to hand in their calendar for data storage and to assess adherence to treatment. If adherence was poor (determined by the clinic physiotherapist), the importance of ACT was emphasized and the parents counselled appropriately. Calendars were returned, approximately every three months, for the majority of participants.

After one year follow up, the CF clinic's social worker, who was blinded to group allocation and had an established rapport with clinic patients, conducted a self-designed one on one semi-structured interview with the parent(s)/caregiver(s) regarding physiotherapy management. Quantitative information was collected regarding the technique(s) used in the past year, duration and frequency of each technique; and qualitative information regarding the likes and dislikes of the different techniques used, with reasons for failure to perform technique(s) twice per day during the study period. This end of study interview was added to the protocol to obtain impartial, and honest reflection on adherence to the ACT interventions during the study period, and to gain insights into reasons for noncompliance, and preference. The interview answers were recorded in writing by the 
social worker. No identifying information was available on the documents. It was emphasized that the information provided to the social worker would be used for research purposes only and not for patient management.

\section{Data-analysis}

All data were entered into an Excel spread sheet and analyzed with Statistica (Version 12, StatSoft Inc, Tulsa USA). An intention-to-treat analysis was performed. As the majority of data were skewed (based on the Lilliefors test) and the sample size was small, non-parametric tests were performed. Comparison between the control group and intervention groups on dichotomous data were done using the chi square test and Fisher exact or Yates correction; and numeric outcome parameters were analyzed using the Mann-Whitney $\mathrm{U}$ test. Effect size was calculated for outcome measures which showed, on initial univariate analysis, to have either a significant difference or a trend towards significant between-groups differences. The $r$ value was calculated with the formula $r=z / v N$ and converted into a Cohen's $d$ value by using the formula $d=2 r / v\left(1-r^{2}\right)[16]$. Interpretation of the effect size was based on Cohen's guidelines for small $(d=0.2)$, medium ( $d=0.5)$ and large $(d=0.8)$ effect sizes [17]. Within group analysis was done by using the Wilcoxon matched pairs test. Quantitative results from the interview were presented as number of participants, frequencies of performed techniques and median (IQR) of duration of performed techniques. The qualitative information regarding likes and dislikes of the different techniques as well as the reasons for failure to perform technique(s) twice per day during the study period, was analyzed by identifying common themes or statements.

\section{RESULTS}

\section{Subjects}

A total of 36 children, between the age of one and eight years, were screened. Nineteen children were excluded prior to enrolment due to various reasons (Supplementary file 3). One child, allocated 
152

153

154

155

156

157

158

159

160

161

162

163

164

165

166

167

168

169

170

171

to the control group, was excluded post-enrolment as the diagnosis of CF was questioned by the attending physician. The other participants all had a clear, confirmed diagnosis of CF. Therefore, 16 participants were included in the study (median [IQR] 5.8 [4.3-6.3] years), nine in the intervention group and seven in the control group. All participants completed the one-year clinical trial, with no loss to follow up. Baseline characteristics of participants were similar between groups (Table 1).

\section{Results between groups at 12 months}

No significant differences were seen between the intervention and control group for any of the outcome measures (Table 2 and Supplementary file 2). However, calculation of the effect sizes revealed a medium effect size for 'number of exacerbations during one year' $(d=0.55)$, with fewer exacerbation during one year in the intervention group; and a small to medium effect size for 'days on antibiotic therapy during one year' $(d=0.48)$, for fewer days on antibiotic therapy in the intervention group.

Due to the small number of participants ( $n=2$ in the control and 3 in the intervention group) who performed acceptable lung function tests [based on the quality criteria set by the ATS/ERS [18]], no statistical analyses were performed for this outcome measure.

\section{Results within groups}

There were no significant changes between baseline and end of study for any of the outcome measures in either group (Supplementary file 2). However, large effect sizes for EQ-5D-Y visual analogue scale score, and CFCS subjective subtotal and total scores were observed in favor of the intervention group ( $d=1.07, d=0.87$, and $d=0.86$ respectively). 


\section{After one month}

174

175

Seven of the nine participants in the intervention group completed a written questionnaire with regards to their experience and preference of AAD compared to their ACT regime prior to the study (adapted from Jarad et al. 2010 [13]). Although AAD was not experienced as worse than the previously used ACTs for most aspects of the questionnaire, four of the seven participants would prefer to return to their previously used ACT. Participants remained in their allocated study arm throughout the entire study period, however, these participants were given additional information on the potential benefits of the technique and the clinic therapist had a discussion with participants regarding difficulties of administering the technique. The two participants who would prefer to use $A A D$ instead of their previous $A C T$ indicated that $A A D$ was similar or better on all aspects of the questionnaire. One participant would prefer to combine AAD with their previous ACT.

\section{End of study interview}

An overview of the techniques used and duration can be found in Supplementary files 2 and 3. The themes regarding likes and dislikes per technique are presented in Table 3.

For both groups, percussions and active play were the most preferred techniques during the study period, as they were performed most often, had most likes and least dislikes.

\section{Intervention group}

Two participants were not interviewed at the end of the study, as their primary caregivers were not present at the visit. Therefore, only information on seven of the nine participants in the intervention group is presented.

Four of the seven participants used AAD during the trial. The other three reported not having used $A A D$ throughout the study period. Furthermore, each of the following techniques was used by one 
participant: Flutter, vibrations, ACBT, and blowing water; and five of the participants used additional percussions and active play.

Non-adherence to AAD was due to the following themes: time consuming treatment regime $(n=3)$ and the child resisting treatment $(n=2)$. One participant indicated that there was no reason for nonadherence, and one participant declined to answer this question.

\section{Control group}

In the control group, only three of the seven participants performed twice daily ACT. Techniques performed by participants in the control group during the study period were percussions ( $n=7)$, Flutter ( $n=2)$, vibrations $(n=2)$ and ACBT $(n=1)$. Further, six were engaged in active play/exercise during the day.

Themes for non-adherence in this group were: time consuming treatment regime $(n=3)$, child not being productive/ill $(n=2)$, child vomits after treatment $(n=1)$. Three participants did not provide a reason for non-adherence.

\section{Discussion}

This study did not reveal any significant differences between the intervention (AAD) and control group (standard ACT) for any of its primary and secondary outcome measures. Due to the small number of participants, who poorly adhered to therapy prescription, no conclusions can be made regarding the effectiveness of $A A D$ in children with $C F$ aged one to eight years. However, interesting insights were gained with regards to the outcome measures and the methodology. This can be used to inform the development of future protocols, which could entail multi-center trials to increase sample size.

As no literature is available on $A A D$ in patients with $C F$, no comparison can be made with the current study's results. Although several studies have been published on the use of AD in children with CF, 
only one study by Mcllwaine et al. [19], solely focused on children (aged 12-18 years), comparing AD with PD and percussions performed twice daily, in a two year long term home-based randomized cross-over study [19]. The other studies failed to report separate data for adults and children, for which they cannot be compared to the current study's results.

The primary outcome measure 'number of hospitalizations in one year' was not different between the two groups. This is in line with the results found in a study by Mcllwaine et al [19]. Although the current study's other primary outcome measure, 'number of exacerbations during one year', was not reported by Mcllwaine et al.; they did note that more hospitalizations for pulmonary exacerbations were required for participants in the PD with percussions arm of the study, compared to the AD arm [19]. A small to medium effect size of fewer days on antibiotic therapy in the intervention group was found in the current study, which could suggest that AAD might clear infectious secretions from the lungs, therefore influencing antibiotic need. However other factors might influence antibiotic usage, such as bacterial load and type, manner of antibiotics administration and whether antibiotics were prescribed for long- or short- term use [20]. Therefore, trials with larger sample sizes are required to confirm results.

No significant differences between groups for the current study's secondary outcome measures were found. Although, spirometry, in particularly forced expiratory volume in one second (FEV 1 ), is often recommended for monitoring disease progression in patients with $\mathrm{CF}[5,21]$; improvements in CF management impact the value of $\mathrm{FEV}_{1}$ in monitoring disease progression [22]. Therefore, spirometry might not be the best outcome measure to use in future research studies. Furthermore, parents scored the current health of their children high on the EQ-5D-Y visual analogue scale (medians $>85 / 100)$. This could be a result of the chronic nature of the disease, for which coping mechanisms might have led to adaptations in lifestyle and disease perceptions [10]. No comparison could be made with other studies on AD in the CF population. However, as patients with CF face many challenges throughout their life, assessment of HRQOL is important in this population [23]. Future 
research could investigate the use of the Pediatric Quality of Life Questionnaire for children from the age of five years or the Cystic Fibrosis Questionnaire for children six years and older $[24,25]$. The current study also used the CFCS, which has not been reported in other studies in the CF population. Although there were large effect sizes for subjective and total CFCS scores within the intervention group in the current study, CFCS might not be the most appropriate outcome measure for a one year intervention as it was developed to assess the patient's current clinical status $[12,26]$. The CFCS could be used on a more routine basis, e.g. during each follow up visit, to assess more objectively the presence of an exacerbation and the need for hospitalization.

Mortality was not included as an outcome measure in any of the studies on AD in patients with CF, for which no comparison could be made. However, due to the young age included in the current study, mortality rate might not have been an appropriate outcome measure as mortality at such a young age is uncommon. Although not an intended outcome measure, no adverse events were reported in either arm of the current study.

Finally, a preference for standard ACTs rather than AAD in the participants in the intervention group after one month in the study was revealed. This is in contrast with the study by Mcllwaine et al, where 10 of the 17 participants did not want to return to PD with percussions after completion of the $A D$ arm of the study [19]. This discrepancy between studies could be due to the difference in application of $A D$ and $A A D$, as $A D$ can be performed independently at any time of the day [7]. However, $A A D$ is a passive/assisted technique which requires the caregiver to actively participate in applying the technique $[6,27]$. Two of the four caregivers who reported to use AAD at the end of the study period did mention that $A A D$ was difficult to administer. AAD might therefore require more training of the caregiver, similar to $A D$, where the patient also requires multiple training session before effectively being able to apply the technique [28]. Although, the training of caregivers was performed in a standardized manner, done by the same therapist, with insurance of skill acquisition by demonstration and monitored every follow up to prevent change in the performance throughout 
the study $[29,30]$; one session with three monthly follow up might not be sufficient to master and monitor this more complex technique. For future research, a more intense and regular training program might be needed to train the caregivers in applying AAD. Furthermore, in future studies, it is important to ensure buy-in from participants and parents, as well as monitor adherence to treatment protocol more in depth $[29,30]$. The use of a RCT study design might not be feasible in long-term ACT research, for which other designs should be considered to eliminate the post-randomization drop out [22]. Integration of AAD in the ACT toolkit from an early age could also be beneficial, as caregivers and children get used to the technique and be more comfortable in its application.

Although standard ACTs were preferred to AAD, the adherence to these techniques was also poor. Studies on adherence to ACT and general medical treatment in children with CF reported an overall poor adherence to therapy $(<50 \%)[31]$. Factors influencing treatment adherence of children with CF and their caregivers include: socio-economic status (with maternal education and income higher than $\$ 50000$ identified as positive influencers for adherence); mental health (depression and anxiety, in both the child and the caregiver, negatively influencing treatment adherence); family relationships (supportive parents and a good child-parent relationship positively influencing adherence); timeconsuming therapy; and understanding of the disease progression and necessity of therapy[32-35]. In the current study, the main reason for non-adherence to ACT was the time-consuming nature of the intervention. Adherence to the original daily diary monitoring tools was also poor, for which it was changed to a calendar and sticker system. An end of study subjective interview was added to the protocol to further investigate participants' adherence to ACT. However, this method of data gathering is not objective (self-reported adherence is found to be higher than objectively measured adherence)[36], and the current study failed to audio recorded and transcribed the interviews, nor were the qualitative information analyzed based on a framework. This could have limited the interpretability of the results, and the adherence rates provided in this current study cannot be used for generalization to a broader population. However, if self-reported treatment adherence is higher 
than the actual adherence, the rates of adherence to twice daily ACTs in the current study are worrisome; highlighting the need for the use of an objective adherence monitoring tool to objectively quantify the problem in future studies. Several options have been reported in literature, such as daily telephone calls and electronic devices to monitor adherence $[32,36,37]$. However, these are not always feasible due to high cost and time constraints. Therefore, cost effective methods of adherence follow-up, monitoring adherence more frequently, from early in the study, should be explored, such as SMS, email, apps or online messaging.

This study is the first pilot RCT on the use of AAD in children with CF. The results of this study add to the body of knowledge on AAD as an ACT in this population. This pilot study identified that AAD might be a useful technique to add to the airway clearance 'toolbox' for children with CF as no adverse events were reported and a small to medium effect size for number of days on antibiotic therapy was found, benefiting the intervention group. However, a number of concerns were also identified, mainly poor adherence to home-therapy and no participant in the intervention group solely performing AAD as per pre-set methodology, limiting interpretation of results and feasibility of conducting a full-scale long-term RCT in this population. The pre-specified sample of 30 participants could not be enrolled due to the limited availability of eligible participants at the CF clinic.

\section{CONCLUSION}

Conclusions cannot be made regarding the effectiveness and safety of AAD in children with CF due to the small sample size included in this study and the lack of adherence to the prescribed intervention. Further research is needed to investigate the usefulness of AAD in children of this population and to tackle issues related to treatment adherence. 
315 We would like to thank all the participants and their parents for participating in this study. We would

316 also like to thank medical staff of the CF clinic at Red Cross War Memorial Children's Hospital for

317 their support.

318 


\section{RefERENCES}

3201 Ratjen FA. Cystic fibrosis: pathogenesis and future treatment strategies. Respir Care 2009;54:595-

321 602.http://rc.rcjournal.com/content/54/5/595.short (accessed 4 Oct 2014).

322

323

2 Konstan MW, Berger M. Current understanding of the inflammatory process in cystic fibrosis: onset and etiology. Pediatr Pulmonol 1997;24:137-42.http://www.ncbi.nlm.nih.gov/pubmed/9292910 (accessed 11 Feb 2013).

3 Main E, Prasad A, van der Schans C. Conventional chest physiotherapy compared to other airway clearance techniques for cystic fibrosis. Cochrane Database Syst Rev Published Online First: 2005. doi:10.1002/14651858.CD002011.pub2

$4 \quad$ Lahiri T, Hempstead SE, Brady C, et al. Clinical practice guidelines from the cystic fibrosis foundation for preschoolers with cystic fibrosis. Pediatrics 2016;137:e20151784-e20151784. doi:10.1542/peds.20151784

5 NICE. Pulmonary management in cystic fibrosis - NICE Pathways. NICE Guidel 2018;:120.https://pathways.nice.org.uk/pathways/cystic-fibrosis\#content=view-node\%3Anodespseudomonas-aeruginosa\&path=view\%3A/pathways/cystic-fibrosis/pulmonary-management-in-cysticfibrosis.xml

6 Lannefors L, Button B, Mcllwaine M. Physiotherapy in infants and young children with cystic fibrosis: current practice and future developments. J R Soc Med 2004;97:825.http://www.ncbi.nlm.nih.gov/pmc/articles/PMC1308795/ (accessed 6 Feb 2013).

7 Agostini P, Knowles N. Autogenic drainage: the technique, physiological basis and evidence. Physiotherapy 2007;93:157-63. doi:10.1016/j.physio.2006.07.005

8 Van Ginderdeuren, F Vandenplas Y, Deneyer M, Vanlaethem S, et al. Influence of bouncing and assisted autogenic drainage on acid gastro-oesophageal reflux in infants. Pediatr Pulmonol 2017; [Epub ahea. doi:10.1002/ppul.23677

9 Corten L, Morrow BM. Autogenic drainage in children with cystic fibrosis. Pediatr Phys Ther 2017;29:106-17. doi:10.1097/PEP.0000000000000355

10 Scott D, Ferguson GD, Jelsma J. The use of the EQ-5D-Y health related quality of life outcome measure in children in the Western Cape, South Africa: psychometric properties, feasibility and usefulness - a longitudinal, analytical study. Health Qual Life Outcomes 2017;15:12. doi:10.1186/s12955-017-0590-3

Eidt-Koch D, Mittendorf T, Greiner W. Cross-sectional validity of the EQ-5D-Y as a generic health outcome instrument in children and adolescents with cystic fibrosis in Germany. BMC Pediatr 2009;9:55. doi:10.1186/1471-2431-9-55

Kanga J, Kuhn R, Craigmyle L, et al. Cystic fibrosis clinical score: a new scoring system to evaluate acute pulmonary exacerbation. Clin Ther 1999;21:1343-56. doi:10.1016/S0149-2918(99)80035-6

13 Jarad N, Powell T, Smith E. Evaluation of a novel sputum clearance technique--hydro-acoustic therapy (HAT) in adult patients with cystic fibrosis: a feasibility study. Chron Respir Dis 2010;7:217-27. doi:10.1177/1479972310376082

14 South African Cystic Fibrosis Association. The South African cystic fibrosis consensus document. 5th ed. South African Cystic Fibrosis Association 2017. http://www.sages.co.za/content/images/CFconsensusdocforwebsites.pdf 
Sarnaik A, Heidemann S, Clark J. Respiratory pathophysiology and regulation. In: Kliegman R, Stanton B, St. Geme J, et al., eds. Nelson textbook of pediatrics. Philadelphia: : Elsevier 2016. 1981-92.

Fritz CO, Morris PE, Richler JJ. Effect size estimates: current use, calculations, and interpretation. J Exp Psychol Gen 2012;141:2-18. doi:10.1037/a0024338

17 Cohen J. Statistical power analysis for the behavioral sciences. 2nd ed. Hillsdale, New Jersey, New Jersey: : Lawrence Erlbaum Associates 1988.

18 Miller MR, Hankinson J, Brusasco V, et al. Standardisation of spirometry. Eur Respir J 2005;26:319-38. doi:10.1183/09031936.05.00034805

19 Mcllwaine $\mathrm{M}$, Wong $\mathrm{L}$, Chilvers $\mathrm{M}$, et al. Long-term comparative trial of two different physiotherapy techniques; postural drainage with percussion and autogenic drainage, in the treatment of cystic fibrosis. Pediatr Pulmonol 2010;45:1064-9. doi:10.1002/ppul.21247

20 Mogayzel PJ, Naureckas ET, Robinson KA, et al. Cystic fibrosis pulmonary guidelines: chronic medications for maintenance of lung health. Am J Respir Crit Care Med 2013;187:680-9. doi:10.1164/rccm.201207-11600E

21 Smyth AR, Bell SC, Bojcin S, et al. European cystic fibrosis society standards of care: best practice guidelines. J Cyst Fibros 2014;13:S23-42. doi:10.1016/j.jcf.2014.03.010

22 Main E. Airway clearance research in CF: The 'perfect storm' of strong preference and effortful participation in long-term, non-blinded studies. Thorax 2013;68:701-2. doi:10.1136/thoraxjnl-2012203054

23 Quittner AL, Saez-flores E, Barton JD. The psychological burden of cystic fibrosis. Curr Opin Pulm Med 2016;:187-91. doi:10.1097/MCP.0000000000000244

24 Varni JW, Limbers CA, Burwinkle TM. How young can children reliably and validly self-report their health-related quality of life?: an analysis of 8,591 children across age subgroups with the PedsQL 4.0 Generic Core Scales. Health Qual Life Outcomes 2007;5:1. doi:10.1186/1477-7525-5-1

Modi AC, Quittner AL. Validation of a disease-specific measure of health-related quality of life for children with cystic fibrosis. J Pediatr Psychol 2003;28:535-45. doi:10.1093/jpepsy/jsg044

26 Hafen GM, Ranganathan SC, Robertson CF, et al. Clinical scoring systems in cystic fibrosis. Pediatr Pulmonol 2006;41:602-17. doi:10.1002/ppul.20376

International Physiotherapy Group for Cystic Fibrosis. Physiotherapy for people with cystic fibrosis: from infant to adult. 4th ed. IPG/CF 2009. https://www.ecfs.eu/files/webfm/webfiles/File/Physiotherapy WebPages/blue booklet 2009 website version +1.pdf (accessed 27 Feb 2015).

28 Mcllwaine M. Chest physical therapy, breathing techniques and exercise in children with CF. Paediatr Respir Rev 2007;8:8-16. doi:10.1016/j.prrv.2007.02.013

29 Bellg AJ, Resnick B, Minicucci DS, et al. Enhancing treatment fidelity in health behavior change studies: Best practices and recommendations from the NIH Behavior Change Consortium. Heal Psychol 2004;23:443-51. doi:10.1037/0278-6133.23.5.443

30 Borrelli B. The assessment, monitoring, and enhancement of treatment fidelity in public health clinical trials. J Public Health Dent 2011;71. doi:10.1111/j.1752-7325.2011.00233.x 
Quittner AL, Zhang J, Marynchenko M, et al. Pulmonary medication adherence and health-care use in cystic fibrosis. Chest 2014;146:142-51. doi:10.1378/chest.13-1926

Modi A, Cassedy A, Quittner A, et al. Trajectories of adherence to airway clearance therapy for patients with cystic fibrosis. J Pediatr Psychol 2010;35:1028-37. doi:10.1093/jpepsy/jsq015

Oates GR, Stepanikova I, Gamble S, et al. Adherence to airway clearance therapy in pediatric cystic fibrosis: socioeconomic factors and respiratory outcomes. Pediatr Pulmonol 2015;50:1244-52. doi:10.1002/ppul.23317

Smith BA, Modi AC, Quittner AL, et al. Depressive symptoms in children with cystic fibrosis and parents and its effects on adherence to airway clearance. Pediatr Pulmonol 2010;45:756-63. doi:10.1002/ppul.21238

Modi AC, Quittner AL. Barriers to treatment adherence for children with cystic fibrosis and asthma: what gets in the way? J Pediatr Psychol 2006;31:846-58. doi:10.1093/jpepsy/jsj096

Daniels T, Goodacre L, Sutton C, et al. Accurate assessment of adherence: self-report and clinician report vs electronic monitoring of nebulizers. Chest 2011;140:425-32. doi:10.1378/chest.09-3074 
Corten

TABLE 1. BASELINE CHARACTERISTICS OF PARTICIPANTS

\begin{tabular}{|c|c|c|c|}
\hline Characteristic & Control group, $n=7$ & Intervention group, $\mathrm{n}=9$ & p-value \\
\hline Gender, Male (n) & 4 & 5 & $p=0.671$ \\
\hline Age (years), median (IQR ${ }^{\mathrm{a}}$ ) & $\begin{array}{l}5.7 \\
(3.0-6.0)\end{array}$ & $\begin{array}{l}5.8 \\
(5.5-6.6)\end{array}$ & $p=0.266$ \\
\hline Age diagnosis (months), median (IQR ${ }^{\mathrm{a}}$ ) & $\begin{array}{l}3.0 \\
(0.0-6.0)\end{array}$ & $\begin{array}{l}3.0 \\
(1.0-6.0)\end{array}$ & $p=1.000$ \\
\hline $\begin{array}{l}\text { Age start physio (months), median } \\
\left({ }^{\left(Q R^{a}\right)}\right.\end{array}$ & $\begin{array}{l}4.0 \\
(3.0-6.0)\end{array}$ & $\begin{array}{l}6.0 \\
(2.5-10.5)\end{array}$ & $p=0.563$ \\
\hline $\begin{array}{l}\text { Gestation } \\
\text { - Term (n) } \\
\text { - Preterm (n) } \\
\text { - Unknown (n) }\end{array}$ & $\begin{array}{l}7 \\
0 \\
0\end{array}$ & $\begin{array}{l}7 \\
1 \\
1\end{array}$ & $p=0.964$ \\
\hline History of TB ${ }^{b}(n)$ & 0 & 1 & $p=0.563$ \\
\hline Asthma (n) & 1 & 3 & $p=0.392$ \\
\hline Pancreas insufficient (n) & 7 & 9 & $P=1.000$ \\
\hline $\begin{array}{l}\text { HIVc status } \\
\text { - Negative (n) } \\
\text { - Exposed (n) } \\
\text { - Positive (n) } \\
\text { - Unknown (n) }\end{array}$ & $\begin{array}{l}6 \\
1 \\
0 \\
0\end{array}$ & $\begin{array}{l}7 \\
1 \\
0 \\
1\end{array}$ & $p=0.958$ \\
\hline Genotype & & & $p=0.422$ \\
\hline $\begin{array}{ll}- & \Delta F 508(n) \\
& \Delta F 508 \text { homozygous } \\
& \Delta F 508 \text { unknown } \\
- & 3120(n) \\
& 3120 / G \text { A homozygous } \\
& 3120 / G \text { A heterozygous } \\
-\quad \text { Unknown }(n)\end{array}$ & 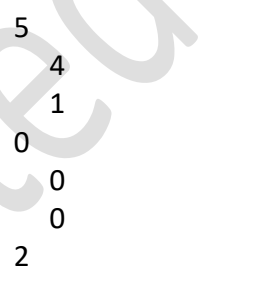 & $\begin{array}{ll}6 & \\
& 5 \\
& 1 \\
3 & \\
& 2 \\
& \\
& 1\end{array}$ & \\
\hline $\begin{array}{l}\text { Colonisation/ } \\
\text { infection } \\
\text { - St. Aureus (n) } \\
\text { - MRSA (n) } \\
\text { - Pseudomonas (n) } \\
\text { - None (n) }\end{array}$ & $\begin{array}{l}4 \\
1 \\
0 \\
2 \\
\end{array}$ & $\begin{array}{l}8 \\
0 \\
1 \\
0 \\
\end{array}$ & $p=0.797$ \\
\hline
\end{tabular}

${ }^{\mathrm{a}} \mathrm{IQR}=$ Interquartile Range; ${ }^{\mathrm{b}} \mathrm{TB}=$ Tuberculosis; $^{\mathrm{C}} \mathrm{HIV}=$ Human Immunodeficiency Virus; ${ }^{\mathrm{d} M R S A}=$ Meticillin-Resistent Staphylococcus Aureus 
Corten

TABle 2. PRimary OUTCOME MEASURES

\begin{tabular}{lrrrrrr}
\hline Outcome measure & \multicolumn{2}{c}{ Control } & \multicolumn{2}{l}{ Intervention } & p-value \\
\cline { 2 - 5 } & Total & Median (IQR) & Total & Median (IQR) & \\
\hline Number of hospitalisations & 4 & $0.0(0.0-1.0)$ & 2 & $0.0(0.0-0.0)$ & 0.791 \\
Days of hospitalisation & 25 & $0.0(0.0-7.0)$ & 19 & $0.0(0.0-7.0)$ & 0.832 \\
Number of exacerbations & 12 & $2.0(1.0-3.0)$ & 10 & $1.0(1.0-1.0)$ & 0.290 \\
Days on antibiotic therapy & 264 & $20.0(10.0-97.0)$ & 167 & $10.0(5.0-15.0)$ & 0.355 \\
\hline
\end{tabular}


Corten

TABLE 3. THEMES IDENTIFYING THE LIKES AND DISLIKES PER AIRWAY CLEARANCE TECHNIQUE

\begin{tabular}{|c|c|c|}
\hline \multirow[t]{2}{*}{ Technique } & \multicolumn{2}{|c|}{ Subjective themes per technique } \\
\hline & Likes & Dislikes \\
\hline $\mathrm{AAD}^{\mathrm{a}}$ & $\begin{array}{l}\text { - It works }(n=2) \\
\text { - Easy }(n=1) \\
\text { - Active technique }(n=1)\end{array}$ & $\begin{array}{l}\text { - Difficult technique }(n=2): \\
\text { didn't get it right }(n=1) \\
\text { - Unsure when to stop }(n=1) \\
\text { - Not easy to distract the child }(n=1) \\
\text { - Less cough production }(n=1) \\
\text { - Child tires easily }(n=1) \\
\text { - Child needs to actively cooperate }(n=1\end{array}$ \\
\hline Flutter & $\begin{array}{l}\text { - It works }(n=2) \\
\text { - Easy }(n=1) \\
\text { - Feel the vibration/feel that is does something }(n=1)\end{array}$ & $\begin{array}{l}\text { - Feels like a duty }(n=1) \\
\text { - Child vomits after the technique }(n=1) \\
\text { - Nothing }(n=1)\end{array}$ \\
\hline Percussions & $\begin{array}{l}\text { - Easy }(n=6) \\
\text { - It works }(n=2) \\
\text { - Routine/been doing it from the beginning }(n=2) \\
\text { - Parent feels what he/she is doing }(n=1) \\
\text { - Bonding and adaptable }(n=1) \\
\text { - Cough augmentation }(n=1) \\
\text { - Sleeps better }(n=1) \\
\text { - Relaxing }(n=1)\end{array}$ & $\begin{array}{l}\text { - Nothing ( } n=6) \\
\text { - Time consuming ( } n=2) \\
\text { - Scared to hurt the child }(n=2) \\
\text { - Feels like a duty }(n=1) \\
\text { - Needs to convince child }(n=2) \\
\text { - Painful hands ( } n=1)\end{array}$ \\
\hline Vibrations & $\begin{array}{l}\text { - Effective }(n=1) \\
\text { - Easy }(n=1)\end{array}$ & $\begin{array}{l}\text { - Time consuming }(n=1) \\
\text { - Feels like a duty }(n=1) \\
\text { - Not sure how to perform technique }\end{array}$ \\
\hline $\mathrm{ACBT}^{\mathrm{b}}$ & $\begin{array}{l}\text { - It works }(n=1) \\
\text { - Easy to motivate the child }(n=1)\end{array}$ & $\begin{array}{l}\text { - Feels like a duty }(n=1) \\
\text { - Nothing }(n=1)\end{array}$ \\
\hline Active play & $\begin{array}{l}\text { - Active }(n=3) \\
\text { - Parents are happy when child tires }(n=2) \\
\text { - Fun }(n=1) \\
\text { - Gets out frustrations }(n=1) \\
\text { - No extra effort }(n=1) \\
\text { - Independent }(n=1) \\
\text { - Clears secretions }(n=1) \\
\text { - Keeps child busy }(n=1) \\
\text { - Parent can see that the child is healthy }(n=1) \\
\text { - Child can be him/herself }(n=1)\end{array}$ & $\begin{array}{l}\text { - Nothing }(n=5) \\
\text { - Needs to observe the child }(n=1) \\
\text { - Fear of dehydration }(n=1 \\
\text { - Child destroys furniture }(n=1)\end{array}$ \\
\hline Other: blowing water (bubble PEPc) & - It works $(n=1)$ & - none $(n=1)$ \\
\hline
\end{tabular}


Corten

\section{SUPPLEMENTARY FILE 1. TRAINING OF CAREGIVERS}

At baseline, all parents in both groups received one on one education on the disease and the importance of regular physiotherapy for airway clearance. Thereafter, the clinic therapist explained the principle(s) of the selected technique(s) at a language level deemed appropriate by the physiotherapist; the technique(s) were demonstrated and then the parents showed the therapist how they would perform the technique. The therapist made corrections to the parent's handling if necessary. The parents were encouraged to ask questions during the entire teaching session and afterwards time was given to reflect on the handling and addressing questions. Finally the parents were asked to demonstrate the technique without feedback from the physiotherapist to make sure they understood it entirely. When the performance was inadequate, the physiotherapist gave more feedback to ensure the parents knew how to perform the treatment. Only when an adequate level of performance (without feedback) was achieved by the parents, were they included in the study [4042]. The training took $15-30$ minutes, depending on individual needs. The parents were given contact information for the physiotherapist if they had any questions or concerns. All training was conducted one on one with the parents and the same clinic therapist. 


\section{SUPPLEMENTARY FILE 2: ADDITIONAL TABLES}

\section{SECONDARY OUTCOME MEASURES FOR THE CONTROL AND INTERVENTION GROUPS, PRESENTED AS MEDIAN AND IQR}

\begin{tabular}{|c|c|c|c|c|c|c|c|c|c|c|c|}
\hline \multirow{2}{*}{$\begin{array}{l}\text { Outcome measure } \\
\text { Category }\end{array}$} & \multirow[b]{2}{*}{ Outcome } & \multicolumn{2}{|c|}{ Control } & \multicolumn{2}{|r|}{ Intervention } & \multicolumn{2}{|c|}{$\begin{array}{r}\text { Change over time: median } \\
\text { differences }\left(95 \% \mathrm{Cl}^{\mathrm{a}}\right)\end{array}$} & \multicolumn{2}{|c|}{$\begin{array}{r}\text { Between groups at } \\
\text { baseline and end }\end{array}$} & \multicolumn{2}{|c|}{$\begin{array}{l}\text { Within group from } \\
\text { baseline to end }\end{array}$} \\
\hline & & Baseline & End & Baseline & End & Control & Intervention & Baseline & End & Control & Intervention \\
\hline \multirow{3}{*}{$\begin{array}{l}\text { CFCS }^{b} \\
n=7 \text { control } \\
n=9 \text { intervention }\end{array}$} & Subjective & $\begin{array}{r}8.0 \\
(7.0-11.0)\end{array}$ & $\begin{array}{r}8.0 \\
(6.0-12.0)\end{array}$ & $\begin{array}{r}11.0 \\
(10.0-12.0)\end{array}$ & $\begin{array}{r}8.0 \\
(6.0-11.0)\end{array}$ & $0.0(-4.2-4.2)$ & $-3.0(-6.0-0.0)$ & $p=0.072$ & $p=0.832$ & $p=0.753$ & $p=0.091$ \\
\hline & Objective & $\begin{array}{r}6.0 \\
(6.0-8.0)\end{array}$ & $\begin{array}{r}7.0 \\
(5.0-8.0)\end{array}$ & $\begin{array}{r}6.0 \\
(6.0-7.0)\end{array}$ & $\begin{array}{r}6.0 \\
(5.0-6.0)\end{array}$ & $1.0(-1.9-3.9)$ & $0.0(-1.3-1.3)$ & $p=1.000$ & $p=0.341$ & $p=0.787$ & $p=0.418$ \\
\hline & Total & $\begin{array}{r}13.0 \\
(13.0-19.0)\end{array}$ & $\begin{array}{r}14.0 \\
(11.0-22.0)\end{array}$ & $\begin{array}{r}17.0 \\
(17.0-18.0)\end{array}$ & $\begin{array}{r}14.0 \\
(12.0-16.0)\end{array}$ & $1.0(-5.1-7.1)$ & $-3.0(-6.7-0.7)$ & $p=0.204$ & $p=0.958$ & $p=1.000$ & $p=0.093$ \\
\hline $\begin{array}{l}E Q-5 D-Y c \\
n=7 \text { control } \\
n=9 \text { intervention }\end{array}$ & VAS $^{d}$ score & $\begin{array}{r}91.0 \\
(90.0-99.0)\end{array}$ & $\begin{array}{r}95.0 \\
(75.0-100.0)\end{array}$ & $\begin{array}{r}85.0 \\
(80.0-95.0)\end{array}$ & $\begin{array}{r}92.5 \\
(90.0-10.00)\end{array}$ & $4.0(-19.6-27.6)$ & $7.5(-6.4-21.4)$ & $p=0.315$ & $p=0.721$ & $p=0.917$ & $p=0.068$ \\
\hline \multirow{3}{*}{$\begin{array}{l}\text { Anthropometry } \\
n=7 \text { control } \\
n=9 \text { intervention }\end{array}$} & $\begin{array}{l}\text { BMI'-for-age z- } \\
\text { score }\end{array}$ & $\begin{array}{r}0.3 \\
(-1.0-2.3)\end{array}$ & $\begin{array}{r}-0.7 \\
(-1.4-1.8)\end{array}$ & $\begin{array}{r}0.1 \\
(-0.2-0.4)\end{array}$ & $\begin{array}{r}-0.3 \\
(-0.5-0.1)\end{array}$ & $-1.0(-3.9-1.95)$ & $-0.4(-0.9-0.2)$ & $p=0.751$ & $p=0.672$ & $p=0.735$ & $p=0.139$ \\
\hline & $\begin{array}{l}\text { Weight-for-age } \\
\text { z-score }\end{array}$ & $\begin{array}{r}-1.2 \\
(-1.5-0.4)\end{array}$ & $\begin{array}{r}-1.0 \\
(-1.5-1.5)\end{array}$ & $\begin{array}{r}-1.0 \\
(-1.1-(-0.5))\end{array}$ & $\begin{array}{r}-0.8 \\
(-1.4-(-0.1))\end{array}$ & $0.2(-2.7-3.1)$ & $0.2(-1.0-1.4)$ & $p=0.832$ & $p=1.000$ & $p=0.612$ & $p=0.767$ \\
\hline & $\begin{array}{l}\text { Height-for-age } \\
\text { z-score }\end{array}$ & $\begin{array}{r}-0.6 \\
(-1.9-0.2)\end{array}$ & $\begin{array}{r}-0.3 \\
(-1.6-(-0.1))\end{array}$ & $\begin{array}{r}-1.3 \\
(-1.5-(-0.8))\end{array}$ & $\begin{array}{r}-1.0 \\
(-1.6-0.2)\end{array}$ & $0.3(-2 .-3.2)$ & $0.3(-1.0-1.6)$ & $p=0.525$ & $p=0.916$ & $p=0.237$ & $p=0.260$ \\
\hline
\end{tabular}

${ }^{\mathrm{a}} \mathrm{Cl}=$ Confidence Interval; ${ }^{\mathrm{b}} \mathrm{CFCS}=$ Cystic Fibrosis Clinical Score; ${ }^{\mathrm{C}} \mathrm{EQ}-5 \mathrm{D}-\mathrm{Y}=$ EuroQol 5 Dimensions Youth version; ${ }^{\mathrm{e}} \mathrm{dAS}=$ Visual Analogue Scale; ${ }^{\mathrm{e}} \mathrm{BMI}=\mathrm{Body}$ Mass Index 
Corten

\section{DURATION AND FREQUENCY OF ACTS USED DURING THE STUDY PERIOD}

\begin{tabular}{|c|c|c|c|c|}
\hline Technique & Intervention $(n=7)$ & & Control $(n=7)$ & \\
\hline & Frequency & Median $\left(\mathrm{IQR}^{\mathrm{a}}\right.$ ) time per session (minutes) & Frequency & Median (IQR ${ }^{\mathrm{a}}$ ) time per session (minutes) \\
\hline \multirow[t]{2}{*}{$A A D^{b}$} & Daily $(n=3)$ & $7.0(1.0-15.0)$ & - & - \\
\hline & Not daily $(n=1)$ & & & 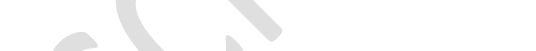 \\
\hline \multirow[t]{2}{*}{ Flutter } & Daily & 10.0 & Daily $(n=1)$ & $3.0(2.0-15.0)$ \\
\hline & & & $3 x / w(n=1)$ & \\
\hline \multirow[t]{5}{*}{ Percussions } & Daily $(n=1)$ & $10.0(5.0-16.0)$ & Daily $(n=1)$ & $15.0(5.0-15.0)$ \\
\hline & Bidaily $(n=1)$ & & Bidaily $(n=3)$ & 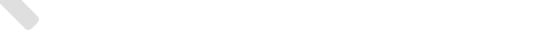 \\
\hline & $3 x / d(n=1)$ & & $3 x / w(n=1)$ & \\
\hline & Not daily $(n=1)$ & & $4-5 x / w(n=1)$ & \\
\hline & When sick $(n=1)$ & & When sick $(n=1)$ & \\
\hline Vibrations & Not daily & $N / A^{c}$ & Bidaily & $2.0(2.0-2.0)$ \\
\hline $\mathrm{ACBT}^{\mathrm{d}}$ & Not daily & $N / A^{c}$ & Daily & 1.0 \\
\hline Active play & Daily & $105.0(45.0-180.0)$ & Daily & $75.0(60.0-75.0)$ \\
\hline Other: blowing & Bidaily & $N / A^{c}$ & - & - \\
\hline
\end{tabular}

${ }^{\mathrm{a}} \mathrm{QR}=$ Interquartile Range; ${ }^{\mathrm{b}} \mathrm{AAD}=$ Assisted Autogenic Drainage; ${ }^{\mathrm{C}} \mathrm{N} / \mathrm{A}=$ Not Available; ${ }^{\mathrm{d} A C B T}=$ Active Cycle of Breathing Technique; ${ }^{\mathrm{e}} \mathrm{PEP}=\mathrm{Positive} \mathrm{Expiratory}$ Pressure therapy 
Corten

SUPPLEMENTARY FILE 3: FIGURES

\section{FigURE LEGEND}

Figure 1. Procedural flow diagram

Figure 2. Study flow diagram

Figure 3. Number of participants using various ACTs during the study period 


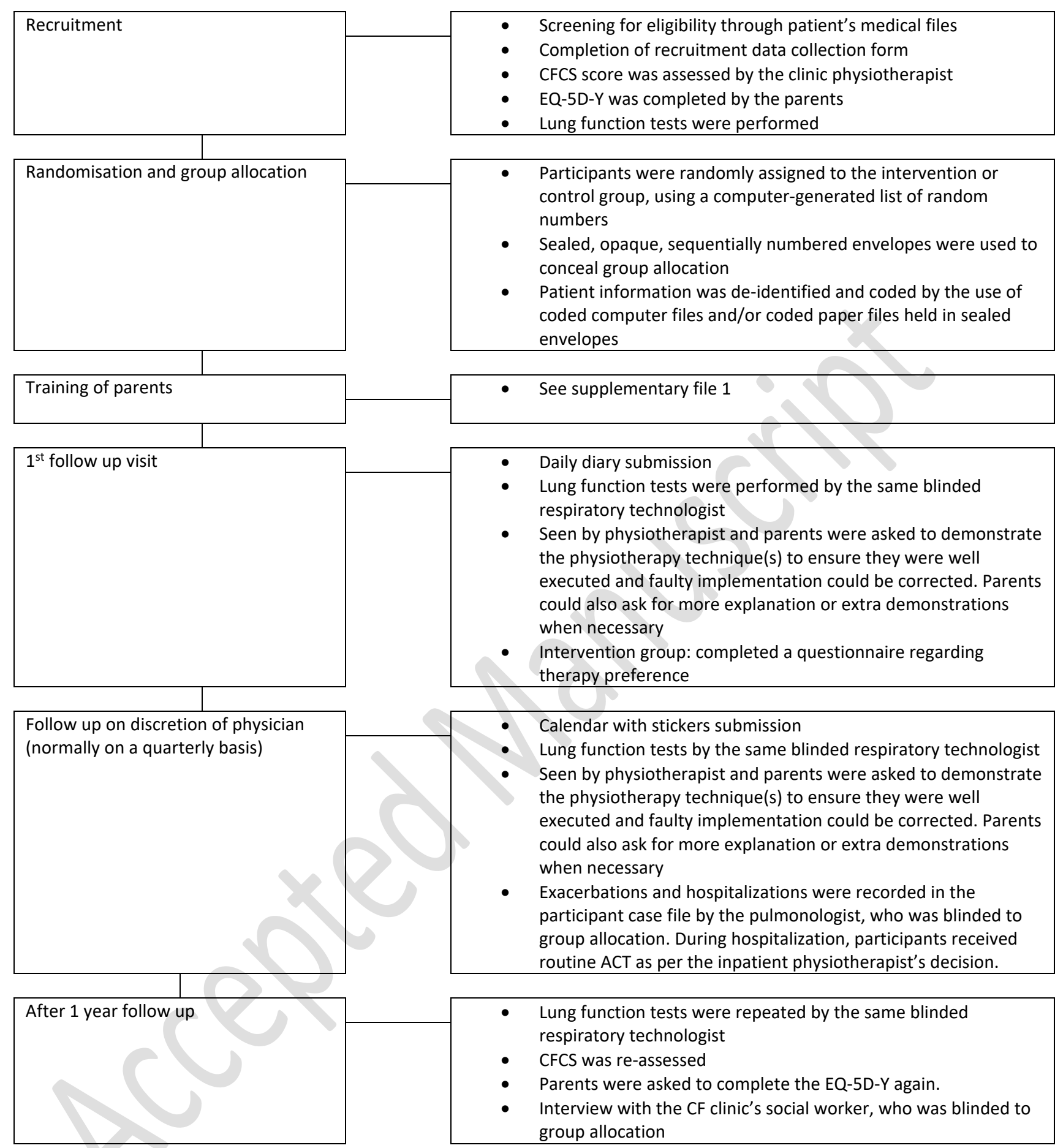

Figure 1. Procedural flow chart 


\section{Corten}

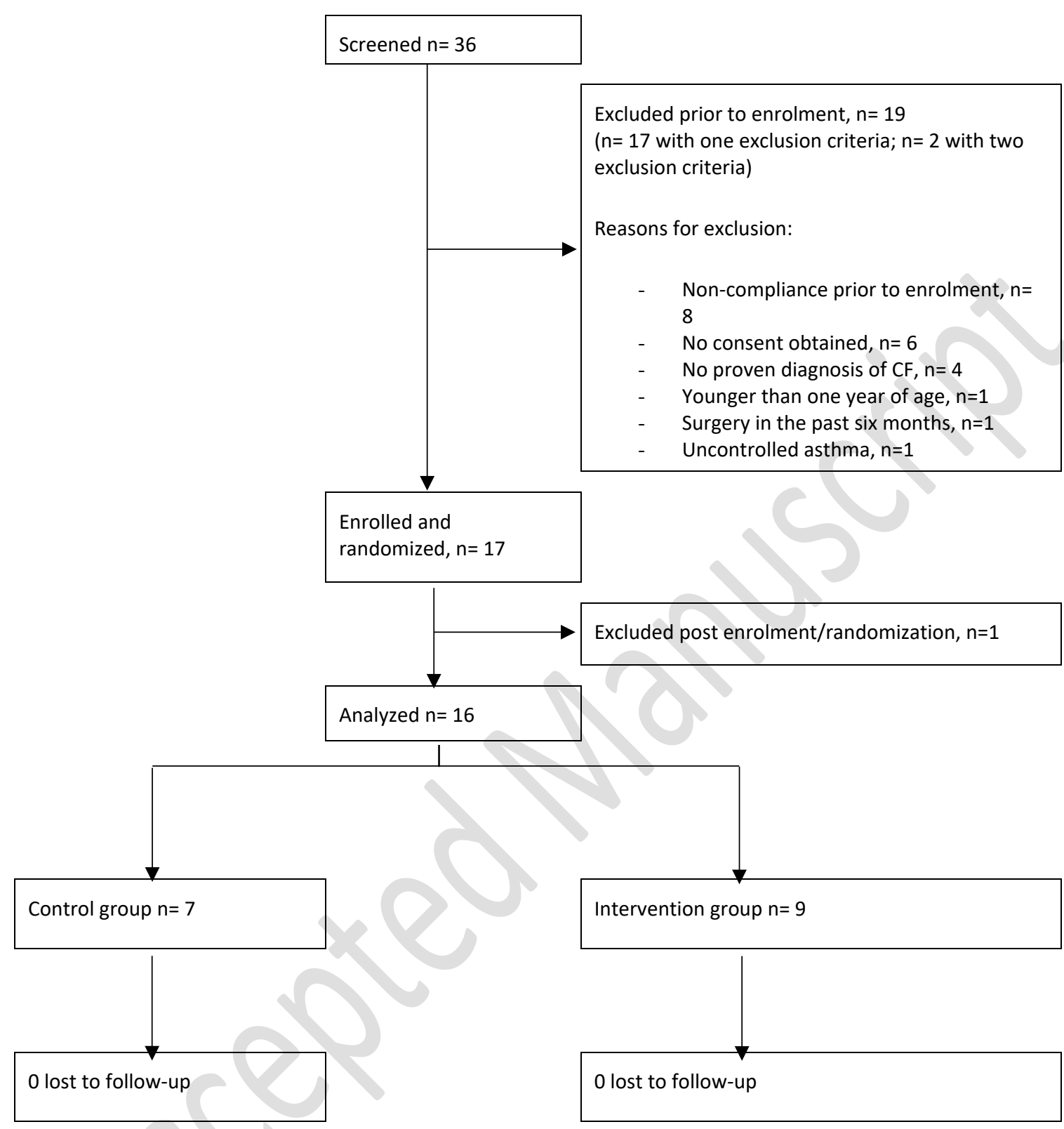

Figure 2. Study flow diagram 


\section{Corten}

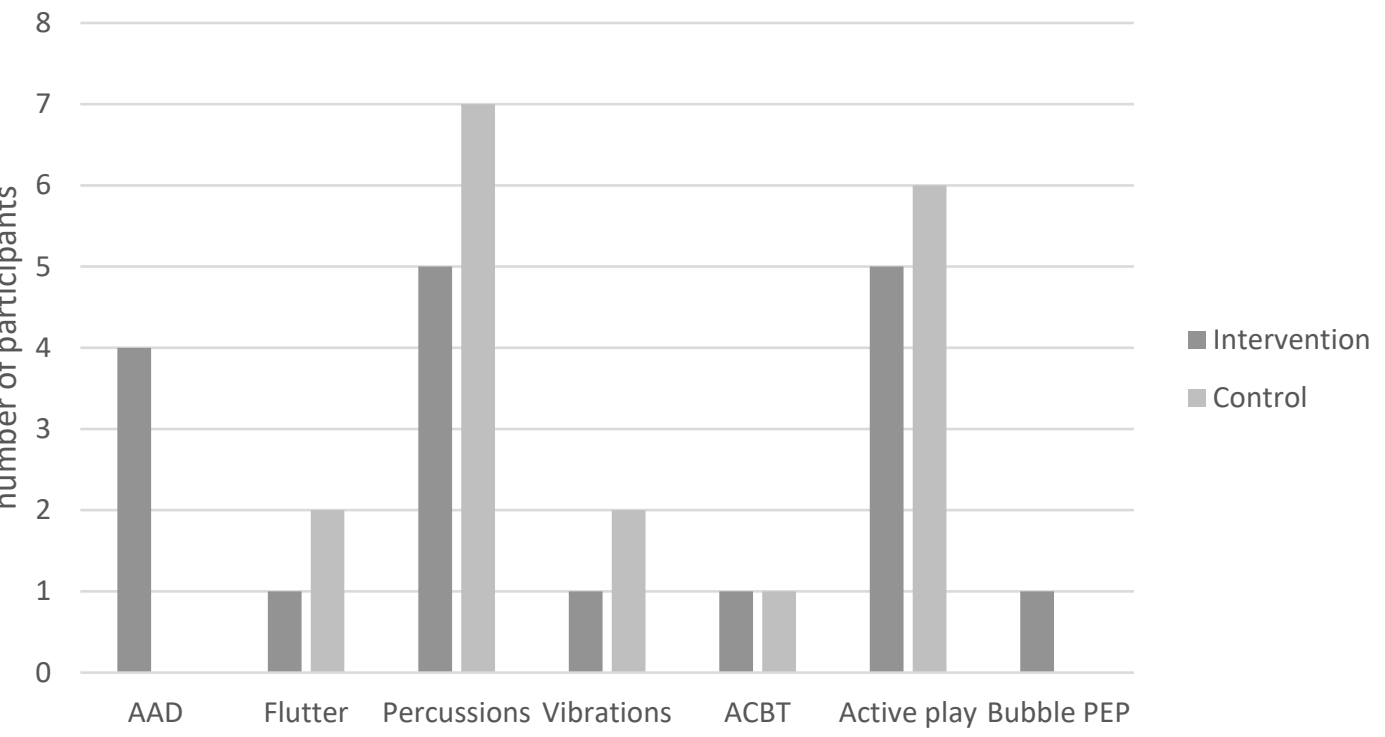

Figure 3. Number of participants using various ACTs during the study period 